\title{
WOMEN'S OCCUPATIONAL DISTRIBUTION AND
}

\section{ITS IMPACT ON EMPOWERMENT}

\section{DR. LAKHIMI NATH}

Assistant Professor, Department of Economics, Pandit Deendayal Upadhyaya Adarsha Mahavidyalaya, Assam, India

\begin{abstract}
This paper primarily deals with the empowerment of women with respect to occupation distribution. In other words, how occupation distribution impact on women empowerment. The geographical area selected for the study is the rural areas of Nagaon district of Assam. Nagaon district is one of the economical backward districts of Assam. The sample size selected for the study is 170 from rural areas of Nagaon district of Assam. The target group population selected for the study is women belonging to the age group of 18-60 years. Fussy set technique has been applied here for the analysis of data. The results show that occupation distribution has a greater impact on women empowerment. In the paper the women empowerment is measured in terms of three attributes, such as decision making within the family, women's control over economic resources and women's political participation.

KEYWORDS: Empowerment, Women Empowerment, Fuzzy Set Technique \& Occupation Distribution of Women
\end{abstract}

Received: Mar 07, 2019; Accepted: Mar 27, 2019; Published: May 18, 2019; Paper Id.: IJHRMRJUN201916

\section{INTRODUCTION}

Women constitute almost $50 \%$ of the world's population. But in India disproportionate sex ratio has been found where female's population has been comparatively lower than males. As far as their social status is concerned, they are not treated as equal to men in all the places. In the Western societies, the women have got equal right and status with men in all walks of life. But gender disabilities and discriminations are found in India even today. The paradoxical situation has such that she was sometimes concerned as Goddess and at other times merely as slave. In Indian society, a female is always dependent on male members of the family even till today. A female is not allowed to speak with loud voice in the presence of elder members of her in-laws. Besides these, as a widow her dependence on male members of the family still more increases. In many social activities she is not permitted to mix with other members of the family. Other hand, she has very little share in political, social and economic life of the society. Like in India, in Assam also women face various kinds of discrimination. The status of women in Assam is very low in almost all aspects.

Empowerment is the process by which one can gain control over her/his own resources and the circumstances of her/his life. Therefore, empowerment of women can be viewed as a way of creating social environment in which women can make decision of their own life and can make choices individually. Empowerment refers to increasing spiritual, economic, political, social, educational and gender strength of individuals and communities. The concept of empowerment is multidimensional. Empowerment can be viewed as economic empowerment, social empowerment, political empowerment, educational empowerment, community empowerment etc. Although a considerable debate on what constitutes empowerment exists, according to Kabeer's 
(2001) definition empowerment implies "the expansion in people's ability to make strategic life choices in a context where this ability was previously denied to them."

Since women empowerment is a prerequisite for economic development, this study aims at analyzing the level of women empowerment in a remote economically backward region of Assam. The geographical area selected for the study is rural areas of Nagaon district of Assam. Here a pioneering attempt is made here to study the level of women empowerment in the rural areas of Nagaon district of Assam and to examine its linkage with the occupational distribution of the women of the district. The second objective of examining the linkage between women empowerment and their occupation has been taken up because this area has remained largely unexplored till date in the domain of research on empowerment.

\section{OBJECTIVES}

The objectives of the study are as follows.

- To assess the level of women empowerment by constructing and estimating women empowerment index.

- To examine the linkage between women empowerment and their occupational distribution.

\section{METHODOLOGY AND THE DESIGN OF THE STUDY}

The study is based on primary data and the target group population comprises of adult women belonging to 18-60 age group. Identification of this group is in the line of the study that focuses on empowerment and workforce participation of women. A sample of 170 women respondents in the age group of 18-60 years from 170 households is selected for the study at random from the rural areas of the district of Nagaon. A structured interview schedule is used for collecting primary data through household survey. Direct interview method is followed and the data are collected from both employed and unemployed women.

The basic segments which constitute the level of women empowerment are their ability to take decision within family, women's control over economic resources and women's political participation. The variables which are used in this study to measure women empowerment in its above mentioned three constituent parts are defined below.

\section{Decision Making within Family}

Decision making power of women is an important constituent of women empowerment. The decision making ability of women within the family is judged by their decision making power in regard to Family Health Care, Larger household purchase, Family size, Job of women, Going outside home of any member, Family day to day expenditure and spending personal income. All the variables are quantified as

- Entirely by the respondent-1

- Partially by the respondent- 0.5

- No participation of the respondent-0

\section{Women's Control over Economic Resources}

The control over economic resources of women is measured by taking into account the variables- Routine household spending, Purchasing jewelry/ bonds/shares, Purchasing gifts for relatives, Control the savings for use, Purchasing clothes and make-up articles, Own and control household variables, Sale/ purchase or exchange land/ house/ 
livestock, Education/expense on children, Purchasing daily foods, To open bank account/ insurance policy by their names.

All the above variables are quantified as

- $\quad$ Entirely by the respodent-1

- $\quad$ Partially by the respondent- 0.5

- No participation of the respondent- 0

\section{Political Participation}

The variables which define the constituent part Political Participation of women empowerment are Ability to cast vote in election, Vote to a candidate of choice, Attend the speeches of the election candidates, Update self about the political system and, Talk to political leaders/representatives in need.

All the above variables are quantified as

- $\quad$ Entirely by the respodent-1

- $\quad$ Partially by the respondent- 0.5

- No participation of the respondent- 0

Fuzzy set technique is used to analyze and interpret the data in the study. The notion of fuzzy set was first introduced by Zadeh in 1965 when he defined fuzzy set as "a class of objects with a continuum of grades of membership". The fuzzy set theory have been applied in different frameworks, for example to measure poverty [Cerioli, Zani, (1990); Lemmi, Betti, (2006)]; well-being [(Chiappero, Martinetti,(2000); Baliamoune-Lutz, (2004)]; quality of life (Lazim, Osman, (2009)); customer satisfaction for a service [Zani, Milioli, Morlini, (2012)], or satisfaction of graduates with the suitability of university education for working purposes (Crocetta, Del Vecchio, 2007).

The fuzzy set approach in this paper is applied to analyze the empowerment of women in rural areas of Nagaon district. The mathematical framework of the same is presented below.

Let $\mathrm{X}$ be a set of population and $\mathrm{E}$ is the fuzzy subset which represents the set of empowered women. The degree of membership to the fuzzy set $\mathrm{E}$ of the $i$-th individual $(i=1, \ldots, n)$ with respect to the $j$-th constituents $(j=1, \ldots, m)$ is defined as

$$
\mu_{E}\left(X_{j}\left(a_{i}\right)\right)=x_{i j} \quad o \leq x_{i j} \leq 1
$$

Where

- $\quad x_{i j}=1$ if the $i$-th individual is fully empowered with respect to the $j$-th constituents;

- $\quad x_{i j}=0$ if the $i$-th individual is not empowered with respect to the $j$-th constituents

- $\quad o \leq x_{i j} \leq 1$ if the $i$-th individual is partially empowered with respect to the $j$-th constituents with an intensity belonging to the open interval $(0,1)$. 
The empowerment index of the $i$-th individual $\mu_{E}\left(a_{i}\right)$ i.e. the degree of membership of $i$-th individual to the fuzzy set $E$ is defined as the weighted average of $x_{i j}$,

$$
\mu_{E}\left(a_{i}\right)=\sum_{j=1}^{m} x_{i j} w_{j} / \sum_{j=1}^{m} w_{j}
$$

Where $w_{j}$ the weight attached to the $j$-th constituents. The empowerment index $\mu_{E}\left(a_{i}\right)$ measures the degree of empowerment of the $i$-th individual as a weighting function of the $\mathrm{m}$ constituents. Hence, it measures the intensity to empowerment of the $i$-th individual subject to women's decision making, control over economic resources and political participation.

The weight $w_{j}$ attached to the $j$-th constituents stand for the intensity of empowerment of $X_{j}$. A formula to calculate weight is proposed by Cerioli and Xani (1990) and can be represented in the following form-

$$
w_{j}=\log \left[n / \sum_{i=1}^{n} x_{i j}\right] \geq 0
$$

Finally, the empowerment index of the population $\mu_{E}$ is simply obtained as a weighted average of the empowerment index of the $i$-th individual $\mu_{E}\left(a_{i}\right)$

$$
\mu_{E}=1 / n \sum_{i=1}^{n} \mu_{E}\left(a_{i}\right)
$$

While the multidimensional empowerment index for the $i$-th individual $\mu_{E}\left(a_{i}\right)$ is the weighted average of $x_{i j}$ with weight $w_{j}$, the unidimensional empowerment index for the $j$-th constituents is the average of $x_{i j}$ :

$$
\mu_{E}\left(X_{j}\right)=1 / n \sum_{i=1}^{n} x_{i j}
$$

In this way it is possible to get the multidimensional empowerment index of the population $\mu_{E}$ as the weighted average of $\mu_{E}\left(X_{j}\right)$ with weight $w_{j}$ :

$$
\mu_{E}=1 / n \sum_{i=1}^{n} \mu_{E}\left(a_{i}\right)=\sum_{j=1}^{m} \mu_{E}\left(X_{j}\right) w_{j} / \sum_{j=1}^{m} w_{j}
$$

In order to define the degree of membership $x_{i j}$ to the set $\mathrm{E}$ of the $i$-th household, $i=1,2, \ldots, n$ with respect to the $j$-th indicator, $j=1,2, \ldots, m$ it is possible to follow a three steps procedure-

First, for each indicator $X_{j}$ it is necessary to build a table containing the possible simple or composite outcomes of $X_{j}$.

Second, to each outcome it is associated a value, in the closed unit interval [0,1], which represents, for the $j$-th indicator, the degree of membership to E corresponding to the given outcome. 
Third, for the $i$-th household, $i=1,2, \ldots, n$, the outcome is observed with respect to the $j$-th indicator and it is assigned the corresponding degree of membership to E, which for the $i$-th household is $x_{i j}$.

\section{DATA ANALYSIS, RESULTS AND DISCUSSIONS}

Table 1: Degree of Empowerment \& Weighted Women Empowerment Index

\begin{tabular}{|c|c|c|c|}
\hline Constituents & $\mu_{E}\left(X_{j}\right)$ & $W_{j}$ & $\mu_{E}\left(X_{j}\right) W_{j}$ \\
\hline $\begin{array}{c}X_{1} \text { (Decision making } \\
\text { within the family) }\end{array}$ & 0.4817 & 0.3172 & 0.1528 \\
\hline $\begin{array}{c}X_{2} \text { (Control Over } \\
\text { Economic Resources) }\end{array}$ & 0.4189 & 0.3779 & 0.1583 \\
\hline $\begin{array}{c}X_{3} \text { (Political } \\
\text { participation) }\end{array}$ & 0.5507 & 0.2591 & 0.1427 \\
\hline
\end{tabular}

Source: estimated by the researcher

In Table $1, X_{1}$ represents respondent's decision making power within the family. $X_{2}$ represents respondent's control over economic resources and $X_{3}$ represents respondent's political participation. $\mu_{E}\left(X_{j}\right)$ represents degree to empowerment according to the constituents, $w_{j}$ indicates the weight of the constituents and $\mu_{E}\left(X_{j}\right) w_{j}$ represents weighted women empowerment index.

Now the overall women empowerment index (WEI) is of rural areas of Nagaon district is calculated by using the following formula

$$
\begin{aligned}
& W E I=\sum_{j=1}^{m} \mu_{E}\left(X_{j}\right) w_{j} / \sum_{j=1}^{m} w_{j} \\
& =0.4538 / 0.9542 \\
& =0.4755
\end{aligned}
$$

Thus we can say that the women empowerment level in rural areas of Nagaon district is only 0.4755 in the range of $(0,1)$.

\section{Sub Group Empowerment Decomposition}

It is possible to decompose women empowerment index by sub population. Suppose the total population is divided into $\mathrm{K}$ groups $-S_{k}$, of size $n_{k}(\mathrm{k}=1,2, . ., \mathrm{K})$. The intensity of women empowerment of $i$-th individual of $S_{k}$ is given by

$$
\mu_{E}\left(a_{i}^{k}\right)=\sum_{j=1}^{m} x_{i j}^{k} w_{j} / \sum_{i=1}^{m} w_{j}
$$

Where $x_{i j}^{k}$ is the degree of membership related to the fuzzy sub set $\mathrm{E}$ of $i$-th individual $(i=1,2, \ldots, \mathrm{n})$ of $S_{k}$ with respect to the $j$-th constituents $(j=1,2, . ., \mathrm{m})$. Hence, the fuzzy women empowerment associated with group $S_{k}$ is, 
$\mu_{E}^{k}=1 / n_{k} \sum_{i=1}^{n_{k}} \mu_{E}\left(a_{i}^{k}\right)$

Here total 170 rural respondents are divided into four groups according to their occupational distribution. The groups are as follows.

- Primary Sector- It includes those respondents who are engaged in agriculture, plantation etc.

- Secondary Sector- It includes those respondents who are engaged in different types of business such as big, medium and small scale businesses.

- Tertiary Sector- It includes those respondents who are regular salaried and engaged in various government and non-government services.

- Not employed- It includes those respondents who are not engaged in any valued work. In other words they do not have any income.

After analyzing the data according to the groups the result obtained are shown in Table 2.

Table 2: Occupation Category and Empowerment

\begin{tabular}{|l|c|}
\hline \multicolumn{1}{|c|}{ Group } & WEI \\
\hline Primary sector & 0.3756 \\
\hline Secondary sector & 0.4213 \\
\hline Tertiary sector & 0.6321 \\
\hline Not employed & 0.4012 \\
\hline
\end{tabular}

Source: estimated by the researcher

The graphical representation of the result is shown in Diagram 1.

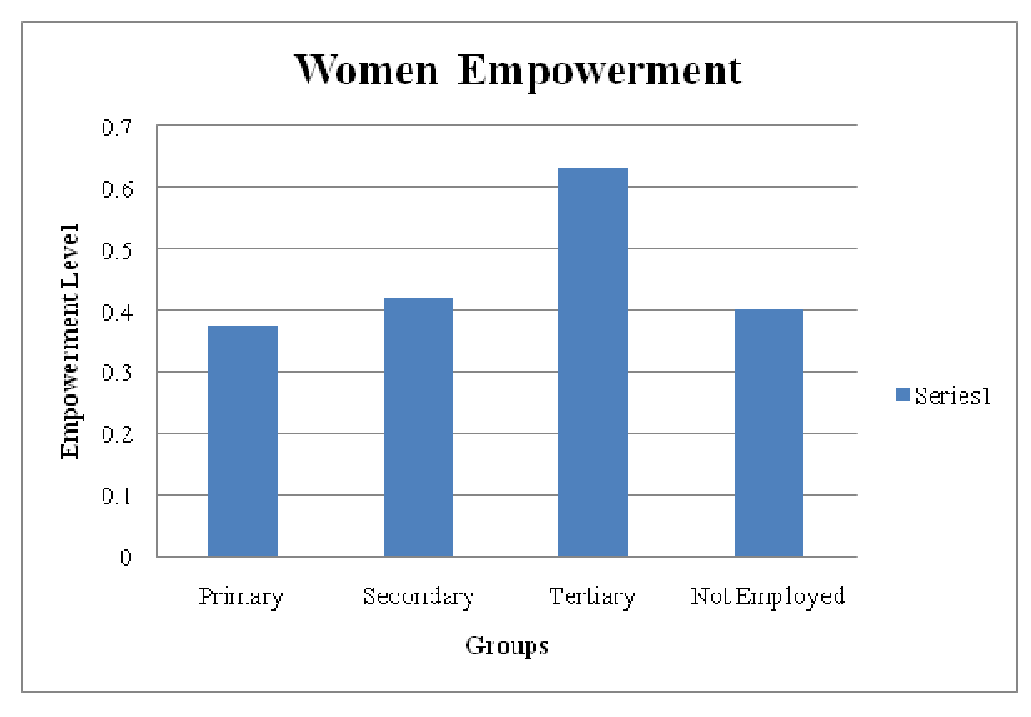

\section{Diagram 1}

From the Table-2 and Diagram-1 it is seen that the respondents who are engaged in primary sector for their livelihood have the lowest level of empowerment which is only 37 percent. The reason for low level of empowerment is that the levels of educational qualification of these women are very low. Besides this the economic condition of such families is very low. Most of such respondents are belonging to below poverty line families. Their participation in different constituents of women empowerment is very low. 
The respondents who are engaged in secondary sector for their livelihood have higher empowerment level than the respondents engaged in primary sector and it is 42 percent. The reason is that the income and economic condition of respondents engaged in secondary sector is higher than those of primary sectors. These respondents are engaged in different types of big, medium or small scale businesses. Besides this, these respondents can participate in different constituents of women empowerment.

Again from the table it is seen that the respondents who are engaged in tertiary sector have the highest level of empowerment which is 63\%. These respondents are engaged in different government and non government sector services. Most of these women are highly educated and their level of income is also high. They are able to participate highly in all the constituents of empowerment.

But it is important to notice that the respondents who are not employed or those who do not earn any income have their employment level as $40 \%$ which is higher than the respondents engaged in primary sectors and lower than the respondents who are engaged in secondary and tertiary sectors. The reason for such variation can be assumed that though these women are not employed but most of these respondents are educated and the economic conditions of these households are sound because their household income is comparatively higher.

From the above discussion it can be concluded that education, occupational distribution of women and economic condition of the household have significant positive impact on women empowerment.

\section{CONCLUSIONS}

The overall average women empowerment level is found to be low in the rural areas of Nagaon district of Assam. The contributions of the three selected constituents to this average women empowerment level is a pointer towards the complex social system of the study area which is more or less similar in other parts of the backward societies of India. The contribution of attribute 'decision making at household level' is found to be only 48 percent while the contribution of other two attributes viz., 'respondent's control over economic resources' and 'political participation' is 41 percent and 55 percent each respectively. This implies that women have relatively less empowerment in control over economic resources. This represents that the economic empowerment of women of rural areas of Nagaon district is low.

Moreover, the link observed in the study between women empowerment and their occupational distribution is in expected line. Women engaged in tertiary sector have highest level of empowerment than the other groups. And women engaged in primary sector have lowest level of empowerment. Therefore, it can be concluded that occupational distribution has a strong impact women empowerment. Policy measures are required to be taken in the direction of generating more paid jobs for the women in secondary and tertiary sectors of Nagaon district of Assam. Besides this, the primary sector should be modernized.

\section{REFERENCES}

1. Bisnath, S. \& Elson, D. (1999), Women's Empowerment Revisited, Background Paper, Progress of the World's Women. UNIFEM.

2. Costa \& Angelis, (2008), The Multidimensional Measurement Of Poverty: A Fuzzy Set Approach, Statistica, Anno Lxviii, Nn. $3-4,2008$

3. Guidelines On Women's Empowerment, United Nations Population Information Network (POPIN). 
4. Handy.F \& Kassam. M, (2004), Women's Empowerment in Rural India, ISTR conference, Toronto Canada July, 2004

5. Kabeer,.N \& et al. (2008), Conceptualising Empowerment And The Implications For Pro Poor Growth, A Paper For The DAC Poverty Network, Institute Of Development Studies.

6. Lather, A \& et al ( 2009 ), Women Empowerment in Urban India :A Study of Working Women Professionals In Delhi, Delhi Business Review, Vol. 10, No. 2 (July - December 2009).

7. Lazim, A. \& Osman. A (2009), A New Malaysian Quality Of Life Index Based On Fuzzy Sets And Hierarchical Needs, Soc Indic Res( 94) Pp. 499-508.

8. L.A. Zadeh, (1965), Fuzzy sets, Information and Control, 8, pp. 338-353

9. Nagaraja. B, (2013), Empowerment of Women in India: A Critical Analysis, IOSR Journal Of Humanities And Social Science (IOSR-JHSS) Volume 9, Issue 2 (Mar. - Apr. 2013), PP 45-52.

10. Naqvi, R. \& Ibrar, M, (2015), Views And Opinion Of Rural Women Of District Multan About Their Involvement And Participation In Family Decisions: A Means For Women's Empowerment In Pakistani Society, International Journal Of Social Science And Humanity, Vol. 5, No. 2

11. Oyekale, O. \& et al., Fuzzy Set Approach To Multidimensional Poverty Decomposition In Rural Nigeria Department Of Agricultural Economics, University Of Ibadan.

12. Naikwade, S., Gopal, R., \& Sippy, N. A Study on Working Women's Attitude Towards Allopathy or Ayurveda \& Yoga System of Medicine for Managing the Lifestyle Diseases with Special Reference to Western Suburbs of Mumbai.

13. World Bank, Engendering Development: Through Gender Equality in Rights, Resources, and Voice, New York: Oxford University Press, 2001. 